\title{
CRER EM ALGUÉM
}

\author{
Marciano Adilio Spica \\ Universidade Estadual do Centro-Oeste
}

RESUMO: Pretendo, neste artigo, introduzir o debate sobre as características da crença em alguém, dando uma descrição não exaustiva do que está envolvido nesta classe de crença. Faço isso usando o texto What Is It to Believe Someone? de Anscombe e o On Certainty de Wittgenstein. Mostro, num primeiro momento, a importância da crença em alguém para nosso conhecimento em geral. Depois disso, apresento, uma tentativa de descrição das principais características desse tipo de crença.

PALAVRAS CHAVE: Crer em alguém, Conhecimento, Wittgenstein, Anscombe.

ABSTRACT: I intend, in this article, to introduce the debate on the characteristics of believe someone, giving a non-exhaustive description of what is involved in this belief class. I do this using the the Anscombe's text What Is It to Believe Someone? and Wittgenstein's On Certainty. I show, at first, the importance of believing in someone to our knowledge in general. After that, I present an attempt to description of the main characteristics of this kind of belief.

KEYWORDS: Believe Someone, Knowledge, Wittgenstein, Anscombe.

Apesar de o tópico "crer em alguém” ser, como bem o diz Anscombe, não só negligenciado, mas, muitas vezes, ignorado na filosofia (cf. Anscombe, 2008, p. 24), nos últimos anos tal tópico tem ganhado bastante relevância dentro das discussões epistemológicas, principalmente, através de discussões sobre o problema do testemunho. Vários são os trabalhos tratando dessa questão, tanto pelo viés da tentativa de uma justificação epistêmica para o testemunho quanto em reflexões voltadas para o impacto do testemunho em áreas filosóficas como a ética, a política e a filosofia da religião. ${ }^{1}$

\footnotetext{
${ }^{1}$ Veja-se por exemplo: COADY, C. A.J. Testimony: A Philosophical Study. Oxford: Oxford University Press, 1995. Ou ainda: LIPTON, P. The Epistemology of Testemony. In.: Studies in History and Philosophy of Science, V 29, n 1, pp. 1-31. Ou: Faulkner, P. Knowledge on Trust.
}

(C) Dissertatio - Volume Suplementar, Junho - 2015 
Neste texto, gostaria de introduzir o debate sobre as características da crença em alguém, tentando dar uma descrição não exaustiva do que está envolvido nesta classe de crença. Farei isso usando um breve texto de Anscombe intitulado What Is It To Believe Someone? e a obra On Certainty de Wittgenstein. Este último parece acreditar que boa parte daquilo que conhecemos ou acreditamos conhecer se dá através do testemunho, do relato de outras pessoas. Apesar de tal ideia aparecer em On Certainty, pode haver divergência quanto ao fato de Wittgenstein estar fazendo uma distinção entre a crença que depositamos em alguém e uma crença que depositamos num fato. Diante disso, o presente trabalho buscará responder à seguinte questão: o que está envolvido numa afirmação do tipo "acredito em $\mathrm{X}$, sendo X uma pessoa qualquer que relata p"? Para deixar mais claro, podemos dizer com Pritchard que a crença que pretendemos abordar é "qualquer crença que alguém razoavelmente e diretamente forma em resposta ao que alguém razoavelmente toma como testemunho e que é essencialmente causada e sustentada por testemunho." (Pritchard, 2004, p. 326). Para cumprir com nossa tarefa, faremos, num primeiro momento, uma breve explanação a respeito da importância que Wittgenstein e Anscombe atribuem àquilo que chamamos crença em alguém para nosso conhecimento em geral. Depois disso, mostraremos como os dois autores entendem a crença em alguém, ou seja, mostraremos as principais características de tal crença.

\section{A importância da "crença em alguém"}

Em 1979 Elisabeth Anscombe escreveu What Is It To Believe Someone?, mostrando o que, para ela, constituiria uma crença em alguém. Ela defende que o tópico crer em alguém é de suma importância para a filosofia da religião (devido à sua óbvia relação com a fé que o religioso deposita em Deus e em textos sagrados), mas

Oxford: Oxford University Press, 2011. Além desses, muitos outros artigos e livros têm sido publicados nos últimos anos, tentando compreender o papel e o estatuto do testemunho no conhecimento em geral. 
também para a teoria do conhecimento em geral, já que grande parte do nosso conhecimento repousa sobre coisas que outras pessoas nos ensinam ou simplesmente nos dizem.

Anscombe defende que a crença em alguém é parte integrante de nosso conhecimento em geral e não pode ser separada dele, ou seja, não podemos distinguir claramente o conhecimento que possuímos devido à crença em alguém e o conhecimento que adquirimos diretamente, através de nossas experiências. Em outras palavras, em nossos discursos, a parte que é crença em alguém não se destaca da parte que é crença direta em algo. Para exemplificar isso, ela usa uma analogia esclarecedora. Cito-a: "Não é que o testemunho nos dê uma parte inteiramente destacável [do conhecimento] como a franja espessa de gordura sobre um pedaço de bife. É mais como as manchas e estrias de gordura que estão distribuídas através da boa carne. Embora, haja pedaços de pura gordura." (Anscombe, 2008, p.26). A analogia de Anscombe nos remete ao fato, nem sempre óbvio, de que nossos discursos estão permeados de crenças em alguém.

Um exemplo interessante para nos fazer ver o quanto tal crença está envolta em nossos conhecimentos cotidianos é o seguinte: Imaginemos que um sujeito $A$ diga que conhece Porto Alegre, não estando em Porto Alegre e não sendo natural de tal cidade. Mais do que isso, o sujeito afirma que conhece Porto Alegre diretamente, ou para usar uma expressão de Russell, conhece tal cidade por acquaintance. Ao responder à pergunta "Você acha que conhece Porto Alegre?" o sujeito $A$ afirma: "Conheço Porto Alegre por que estive lá! Passeei por suas ruas, tomei cerveja na cidade baixa, conheci pessoas que lá habitam e assisti um Grenal.” Mesmo neste caso, poderíamos dizer ao sujeito que afirma conhecer Porto Alegre diretamente que seu conhecimento está envolto de crença em alguém, porque resta aí uma complexa rede de informações que foram transmitidas a ele e que estão na base de sua crença de que realmente conhece tal localidade. Ora, alguém o ensinou que existia um lugar chamado Porto Alegre, que se localizava em um determinado Estado de um determinado País, que sua extensão era tal e tal. Além disso, ensinaram que Porto Alegre era um local diferente daquele que $A$ habitava, que o avião realmente leva ao destino que está dizendo, etc. 
Assim como Anscombe, Wittgenstein também atribui grande importância à crença em alguém. Em On Certainty, tal crença assume um papel primordial já que não só cremos cotidianamente em pessoas que nos transmitem algo, mas, mais importante do que isso, nossa imagem de mundo é construída a partir das crenças que depositamos nas pessoas. Quando crianças, começamos a formar uma imagem de mundo, que será a base para nossas crenças futuras, acreditando nos adultos, sejam eles nossos pais, professores ou autores de livros de história, geografia e diversas outras ciências. É essa crença que depositamos em alguém que faz com que possamos compreender a atividade linguística, formando uma visão de mundo que permite jogar os diversos jogos de linguagem.

A imagem de mundo (Weltbild) é de extrema importância na compreensão wittgensteiniana de como conhecemos. Para ele, todo nosso conhecimento forma um grande sistema e é a partir desse sistema que crenças singulares possuem valor (On Certainty, § 410), ou seja, crenças cotidianas são colocadas à prova a partir de nosso sistema de crenças que é composto por um determinado conjunto de proposições que não colocamos à prova, não questionamos. É esse sistema de proposições que tomamos como inquestionável e que determina o que consideramos válido e o que não consideramos válido e é desse sistema de proposições que partimos para o atuar linguístico ${ }^{2}$.

É importante perceber que Wittgenstein mostra, em vários momentos da obra, o fato de que nossa imagem de mundo (Weltbild) não é adquirida através da investigação racional ou do questionamento, ao contrário, a investigação e o questionamento só são possíveis a partir do momento que acreditamos em um conjunto de proposições básicas. Nesse sentido, é preciso perceber que nossa Weltbild não é aprendida como hipótese científica ou filosófica e nem deve ser confundida com uma atitude de alguém que diga: "Nós não podemos investigar tudo e por isso temos de nos contentar com pressuposições." (On Certainty, §343), o simples fato de emitir uma senteça como essa, pressupõe que tenhamos já uma imagem de mundo, que tenhamos algumas

\footnotetext{
${ }^{2} \mathrm{O}$ conceito de Weltbild está exposto em maiores detalhes em: SPICA, M. A. Weltbild, Bezugssystem e crença religiosa. In: João Carlos Salles. (Org.). Certeza. Salvador: Quarteto, 2012. p. 155-172.
} 
proposições que nos permitam perguntar, duvidar e criar hipóteses. "Isto quer dizer, pertence à lógica de nossa investigação científica que certas coisas não sejam postas em dúvida." (On Certainty, §342). Mas como adquirimos essas crenças que formam nossa imagem de mundo?

Para Wittgenstein, boa parte daquilo que é ponto assente para nós, é dado através da instrução ou de informações repassadas por alguém em quem acreditamos. $\mathrm{Na}$ verdade, podemos dizer que muito daquilo que é ponto assente para nós é adquirido a partir de crença em alguém. Como ele mesmo escreve: "é o sistema de referências herdado que me faz distinguir o verdadeiro do falso" e ainda: "A criança aprende, acreditando no adulto” (On Certainty, $§ 160)$. É por que nos relacionamos desde o início de nossa vida com outros seres que possuem uma linguagem e nos transmitem conhecimento que somos capazes de desenvolver nossas habilidade cognitivas e então jogar a linguagem e produzir conhecimentos. Se não acreditarmos no que outros nos dizem e ficarmos sempre a questionar, nunca nos tornaremos aptos a jogar um determinado jogo de linguagem. $\mathrm{Na}$ verdade, é impossível iniciar a atividade num jogo de linguagem sem antes passar por uma certa instrução nesse jogo. Sem antes crer em alguém. É isso que Wittgenstein quer nos dizer quando escreve: “[...] como é que uma criança pode duvidar imediatamente daquilo que lhe ensinam? Isso só pode significar que ela era incapaz de aprender certos tipos de jogos de linguagem.” (On Certainty, § 283).

Se estamos certos em dizer que nossa imagem de mundo é adquirida, em grande parte, mesmo que não exclusivamente, através de crença em alguém, e a imagem de mundo é algo que está presente em nossas investigações, ou seja, faz parte de nosso atuar cognitivo, sendo o eixo ao redor do qual giram nossas investigações (Cf. On Certainty, § 152), podemos concluir que, para Wittgenstein assim como para Anscombe, a crença em alguém é parte constituinte de todo e qualquer conhecimento, sendo que a mesma não só não deve ser condenada, como é possível dizer que estamos legitimamente justificados em usar a crença em alguém como justificativa de nossos conhecimentos.

Mas, se tanto para Wittgenstein, quanto para Anscombe a crença em alguém é fundamental para nosso conhecimento, e estamos realmente justificados em dizer que boa parte do que conhecemos, conhecemos porque acreditamos em alguém, cabe algumas perguntas: 
quais são as características de crer em alguém? O que diferencia crença em alguém de crença em algo? Pretendemos nos ater, agora, em uma tentativa de resposta a essas questões.

\section{Crer em alguém: uma tentativa de descrição}

A nosso ver, em On Certainty parece haver uma diferenciação entre a crença que depositamos em alguém e a crença num fato. Isso fica claro quando Wittgenstein afirma: "Aprendi uma enorme quantidade de coisas e aceitei-as na base da autoridade de homens; depois achei que algumas dessas coisas se confirmavam e outras não, de acordo com a minha própria experiência” (On Certainty, § 161). Nessa afirmação vemos que quando dizemos que acreditamos em algo porque alguém nos informou a respeito desse algo, nossa crença no fato proferido depende da crença que depositamos em alguém (autoridade dos homens). Não estamos falando meramente de crença que algo existe, mas numa crença de que alguém nos disse que algo existe. Assim sendo, acreditamos porque alguém nos disse. Essa idéia fica mais clara se nos voltarmos ao parágrafo 23 de On Certainty. Aqui Wittgenstein questiona como sei se alguém tem duas mãos quando declara que o tem e ele diz que tal conhecimento é fruto de uma confiança que deposito naquele que me diz. Literalmente, Wittgenstein diz: "acreditarei na sua declaração de que tem duas mãos, se a pessoa em causa for digna de confiança." Fica absolutamente claro que a crença no fato "x tem duas mãos" depende da crença que deposito na pessoa que profere tal sentença.

Para entender melhor isso, imaginemos o seguinte: Existem dois amigos, João e Pedro. Há muitos anos eles não se vêm e Pedro fica sabendo que João sofreu um grave acidente em seu trabalho e, como consequência desse acidente, contaram-lhe que João perdeu uma das mãos. Pedro resolve ligar para seu amigo e pergunta sobre o acidente, afirmando que sente muito que ele tenha perdido uma das mãos. João responde-lhe: -Pedro, eu tenho as duas mãos. Como Pedro acreditaria que João tem duas mãos? Apenas se acreditasse em João. 
Anscombe nos ajuda a entender melhor o tipo de relação que um crente tem com um fato relatado por alguém. Ela cunha a expressão "crença x que p" para caracterizar a crença em alguém. Isso se deve à necessidade de, num primeiro momento, diferenciar a crença em alguém de uma discussão a respeito da diferença entre "crer em" e "crer que”, uma discussão que a mesma evita e não considera importante. Ela afirma não estar interessada numa discussão a respeito de uma "crença em __" a não ser quando "crença em_-" é utilizada significando "crença na existência de _-" já que crer em alguém é sempre e necessariamente também "crer que _-", e seria rídiculo acreditar em alguém que não existe ou acreditar X que X.

Porém, disso não podemos concluir que quando cremos em alguém estamos simplesmente acreditando "que alguém diz", no sentido de simplesmente acreditar que um sujeito x está dizendo algo. Isso seria uma crença do tipo "crer que p", já que estaríamos simplesmente acreditando que algo aconteceu, no caso uma emissão de som ou ruído. Seria uma crença num fato que temos acesso diretamente, como por exemplo, "acredito que o livro está sobre minha mesa" sem que alguém tenha me dito isso, mas pelo fato de eu o ter visto sobre a mesa. Entendemos que Wittgenstein concordaria com essa primeira idéia já que a crença em alguém não é uma mera crença de que este alguém fala, mas de que este alguém fala algo para nós. Só confundiríamos tal coisa se não estivéssemos aptos a jogar o jogo da crença em alguém e não tivéssemos aprendido que, em muitos casos, quando alguém emite sons está emitindo um juízo sobre o mundo e não simplesmente gemendo.

Por outro lado, do fato de que crer em alguém não é simplemsnte crer que alguém diz algo não podemos concluir que "crer em alguém" é simplesmente acreditar que aquilo que ele diz é verdadeiro, pois novamente estaríamos reduzindo uma crença do tipo "crença x que p" a uma "crença que p". Para ilustrar isso, vamos citar um exemplo dado por Anscombe:

Uma testemunha pode ser idagada: 'Por que você acredita que o homem está morto?', e responder: 'Porque o doutor faloume'. Se perguntado adicionalmente qual era seu próprio julgamento, ele poderia responder: 'Eu não tenho minha própria opinião - eu acredito no doutor'. Isso mostra como 
crer $\mathrm{x}$ que $\mathrm{p}$ envolve confiança em $x$ para que $p$.”(Anscombe, 2008, p. 27).

$\mathrm{Na}$ verdade, o que Anscombe mostra com esse exemplo é aquilo que já dissemos anteriormente a respeito do parágrafo 23 de On Certainty, a saber, que não podemos reduzir a crença em alguém a uma crença num fato. Há uma diferença entre acreditar em alguém que relata um fato e acreditar no próprio fato. A crença no próprio fato pode vir da experiência, já a crença em alguém envolve, além do próprio fato relatado, uma espécie de confiança naquele que relata o fato. Quando acreditamos em alguém, estamos acreditando que este alguém também acredita naquilo que ele está proferindo. Novamente, não é uma mera crença no que ele diz, mas uma crença de que ele acredita naquilo que ele diz. É neste sentido que ocorre a dependência de "x para que p".

$O$ fato de que quando acreditamos em alguém estamos acreditando que este alguém acredita no que diz é, a nosso ver, muito bem exposto por Wittgenstein no $\S 288$ de On Certainty, quando ele afirma:

Eu sei não só que a Terra existia muito antes do meu nascimento, mas também que é um grande corpo, que isto foi determinado, que eu e a restante humanidade temos antepassados, que há livros acerca de tudo isso, que esses livros não mentem, etc. E sei tudo isto? Acredito nisso. Este conjunto de conhecimentos foi me transmitido e não tenho motivo para duvidar dele [...].

Mas não só eu sei ou acredito em tudo isso, mas os outros também o fazem. Ou antes, eu acredito que eles acreditam nisso.

Se pensarmos que os outros a que Wittgenstein se refere são aqueles que transmitiram os conhecimentos citados, podemos dizer que acreditar em alguém envolve uma crença de que este alguém também acredita naquilo que transmite. $\mathrm{Na}$ verdade, podemos dizer que nossa crença no fato transmitido depende de acreditarmos que aquele que nos relata tal fato realmente acredita no fato relatado ou tem possibilidade de se certificar do que fala (On Certainty, §23).

Uma objeção que poderia ser feito a isso é que alguém pode relatar algo sem acreditar naquilo que está relatando e eu posso acreditar nele sem pressupor ou ter certeza que ele acredite no que está 
dizendo $^{3}$. Entendemos que isso só seria possível se o falante relatasse um fato como se fosse verdadeiro, ou seja, mesmo que ele não acredite em $\mathrm{p}$, ele relata $\mathrm{p}$ como verdadeiro. Imaginemos que um sujeito $\mathrm{x}$ relate $\mathrm{p}$ a um sujeito $\mathrm{y}$, sem acreditar em $\mathrm{p}$ e isso não é uma anedota. $\mathrm{O}$ sujeito $\mathrm{x}$ relata o fato a y da seguinte forma: "estava vindo à sua casa $\mathrm{e}$ aconteceu p". O sujeito y acredita em x que o fato p aconteceu. Neste caso, o sujeito $\mathrm{x}$ agiu como se acreditasse, ou seja, ele não disse a y que não acredita em $\mathrm{p}$. Se y confia em x como um sujeito razoável, ele confia que $\mathrm{x}$ não o está tentando enganar. Logo, mesmo que $\mathrm{x}$ não acredite em $\mathrm{p}$, agiu como se acreditasse, ao relatar o fato e y acredita em $\mathrm{x}$ porque acredita que $\mathrm{x}$ acredita em $\mathrm{p}$. Uma outra forma de $\mathrm{x}$ relatar $\mathrm{p}$ a y seria a seguinte: "aconteceu $\mathrm{p}$, mas não acredito que $\mathrm{p}$ aconteceu". Neste caso, o relato tomaria outras proporções e a discussão se daria em outro nível, sendo que o acontecimento p ficaria em segundo plano e o que estaria em primeiro plano seria a crença de $\mathrm{x}$ em $\mathrm{p}$. Seria muito mais um relato de uma atitude de $\mathrm{x}$ diante de $\mathrm{p}$ do que um relato de que $\mathrm{p}$ aconteceu. Provavelmente, a discussão tomaria outros rumos e a crença ou não de y se daria não no fato $\mathrm{p}$ mas na atitude de $\mathrm{x}$ em relação a p. A pergunta de y a x seria, provavelmente, algo do tipo: "Como assim: você viu p mas não acredita que p?" A resposta a essa pergunta não é sobre $\mathrm{p}$ ou se $\mathrm{p}$ aconteceu, mas sobre a atitude de $\mathrm{x}$. O que pretendemos reforçar com isso é que em situações normais em que jogamos o jogo do testemunho não o encarando como anedota ou descrição de uma atitude, está envolvida a crença de que aquele que relata acredita no que está relatando.

Isso fica ainda mais claro quando observamos o fato de que não estamos falando genuinamente de crença em alguém, quando sabemos que este alguém está tentando nos enganar. Quando, por exemplo, ele quer fazer uma "pegadinha" conosco, dizendo que um fato $p$ ocorreu em lugar $y$, quando na verdade não ocorreu. Se temos conhecimento anterior de que o fato relatado trata-se de uma brincadeira, não podemos aplicar o conceito “crer em alguém", mesmo que digamos (para fins de dar anadamento ao diálogo) que acreditamos nele. Esse

\footnotetext{
${ }^{3}$ Essa foi uma observação feita ao meu texto por Roberto Pich, a quem agradeço, durante o III Colóquio Wittgenstein em Santa Maria e este parágrafo é uma tentativa, não exaustiva, de resposta a tal observação.
} 
dizer que acredita é, como bem o diz Anscombe, um acreditar num sentido cômico, pois sabemos que aquele que diz algo não acredita naquilo que está dizendo. Nesse sentido, é preciso conhecer o jogo da crença em alguém e o jogo da anedota. Se o conhecemos, conseguimos atuar em ambos sem correr o risco de nos confundirmos e tomarmos relatos cômicos por relatos que tendem a nos transmitir fatos. Mas como aprendemos a fazer essa diferenciação? Poderíamos dizer que nossa habilidade para distinguir entre proferimentos sérios e anedotas é algo que nós adquirimos ao sermos iniciados em uma cultura, em um determinado modo de viver.

Com o que falamos até aqui alguém poderia imaginar que a crença em alguém reduz-se somente a relatos feitos diretamente a outro, porém não podemos nos esquecer que boa parte de nossas crenças em alguém não são adquiridas dessa forma, mas através de relatos escritos. Diante disso, mesmo que pareça uma obviedade é preciso chamar a atenção para o fato de que quando falamos em crer em alguém temos que ter o cuidado para não nos restringirmos a relatos e testemunhos orais, já que muitas de nossas crenças se dão através de relatos escritos, como cartas, jornais, declarações, livros, etc. Como bem o diz Wittgenstein boa parte das crenças que possuímos nos são dadas por livros e não colocamos as informações destes livros em dúvida durante um bom tempo de nossa vida. Nesse sentido, é preciso pensar que a informação contida num livro, por exemplo, é escrita por um autor (ou vários) que são pessoas comunicando a outras informações, juízos sobre o mundo e, quando lemos, estamos acreditando em alguém (no autor do livro). É isso que Wittgenstein quer dizer quando fala da importância dos livros na formação de nossa imagem de mundo e de nossas crenças em geral.

Quando nos damos conta dessa variedade de crença em alguém e o quanto ela é importante em nosso conhecimento, podemos dar um passo além e entender mais alguns detalhes em relação a ela. Nesse sentido, Anscombe nos chama a atenção para a questão de que quando acreditamos em alguém, nem sempre acreditamos porque confiamos que ele é a autoridade original daquilo que transmite. Existem pessoas que são autoridade original no sentido de serem aqueles que fazem, vêem ou ouvem originalmente algo. A autoridade original se diferencia daqueles que meramente transmitem informações. Tal pessoa contribui 
com algo, no sentido de ser a primeira a transmitir uma nova informação e faz isso por que é ou testemunha de tal informação ou ela mesmo viveu o fato que está a transmitir. Alguém poderia questionar, inclusive a partir de Wittgenstein, que não existe alguém que possa ser chamada autoridade original, já que todo o conhecimento depende de alguma informação que adquirimos de alguém, de uma certa imagem de mundo que nos é dada.

Entendemos que Anscombe tem uma resposta satisfatória a essa questão. Ela defende que não se pode afirmar que alguém que diga, por exemplo, que comeu uma maçã nesta manhã esteja confiante de que aquilo que comeu foi uma maçã. $\mathrm{Na}$ verdade, ele sabia que era uma maçã, se domina a linguagem corrente. Ou seja, mesmo que ele tenha sido ensinado sobre o que maçã significa não se pode dizer que ele nos transmite informações sobre sua refeição matinal baseado em crença em alguém. Ou seja, quando alguém que comeu uma maçã no café da manhã transmite a sentença “comi uma maçã no café da manhã", ele é considerado autoridade original. Agora, se ele diz que viu uma pintura de Da Vinci, ele não é uma autoridade original, pois depende de uma tradição de informações que lhe mostrem, por exemplo, certas características da pintura de Da Vinci. Cito Ancombe:

\footnotetext{
Assim um falante pode ser uma autoridade original para o fato que ele relata, como seria usualmente o caso se ele relatasse que comeu uma maçã, ou uma autoridade original, mas não totalmente original, se ele dissesse que viu alguma pintura de Leonardo; ou ele pode não ser uma autoridade original na totalidade, se ele dissesse que Leonardo $f e z$ desenhos para uma máquina voadora. Neste último caso, ele certamente conhece de ter ouvido falar, mesmo que tivesse visto os desenhos. (Anscombe, 2008, p. 28)
}

Quando cremos em alguém, mesmo que este não seja autoridade original, isso não implica que não acreditemos nesta pessoa. Ora, é só nos voltarmos para o grande número de crenças que adquirimos através de relacionamentos com pessoas que nos contam coisas de que ouviram falar. Nossos pais, avós, professores, etc. A diferenciação entre autoridade original e não original é importante porque mostra que quando acreditamos em alguém, não estamos simplesmente acreditando que o que ele diz é verdadeiro (cf. Anscombe, 2008, p. 29). Mas estamos 
acreditando nele, independentemente dele ser autoridade original ou não. Anscombe faz uma interessante analogia que, a nosso ver, explica melhor essa idéia. Ela compara dois casos que aparentemente seriam crença em alguém. O primeiro é a crença que temos num intérprete que está traduzindo uma palestra. Não podemos culpar o intérprete, em casos normais, pelas possíveis inverdades da palestra, pois as inverdades são do palestrante e não do intérprete. A crença que depositamos no intérprete é meramente uma crença de que o que ele diz é o que o palestrante diz, ou seja, estamos acreditando que o que ele diz é verdadeiro, porém não estamos acreditando nele no sentido de crer em alguém. Agora, imaginemos um caso em que um professor diz algo ao seus alunos. Neste caso, mesmo que ele "não seja uma autoridade original, está errado se o que ele diz é uma inverdade”, e isso acontece por que neste caso, os alunos acreditam nele. Neste caso, temos crença em $x$ para que $p$, enquanto no caso do intérprete cremos que $p$.

Entendemos que Wittgenstein concordaria com o fato de que quando acreditamos em alguém não necessariamente estamos dizendo que este alguém é uma autoridade original. Ora, boa parte daquilo que lemos nos livros de ciência e acreditamos de pessoas que nos relatam, são coisas que essas pessoas não vivenciaram, mas aprenderam de outros e isso não é um problema, já que boa parte desse aprendizado não é nunca posto em dúvida e, no fundo, não questionamos se aquilo que alguém nos disse é verdadeiro ou falso, mas aceitamos. Como mostramos anteriormente, a dúvida é posterior à crença. E, no ato de crer, não nos perguntamos sobre a autoridade original.

Outro ponto que precisa ficar claro em relação à crença em alguém é o fato de que tal crença envolve um certo conjunto de crenças que estão implícitas no fato de acreditar em $x$ para que $p$. Para Anscombe, há no mínimo mais duas crenças que estão envolvidas no fato de crer em alguém, a saber, (1) a crença de que alguém está comunicando algo e de que (2) é preciso acreditar que o que o trasmissor está relatando é realmente aquilo que ele (o transmissor) entende estar transimitindo, ou seja, é preciso acreditar que o significado daquilo que é transmitido é o significado que realmente o transmissor possui daquilo que é transmitido. Para o segunto tipo de caso, Anscombe chama a atenção que não é dificil saber o que alguém está significando já que "os ruídos naturais e os fenomenos visuais não 
são usualmente ouvidos ou vistos como linguagem e a questão de que se alguém está falando ou se é um trecho de linguagem escrita é raramente uma dificuldade para alguém responder." (Anscombe, 2008, p. 29). Já no caso da crença de que alguém está nos comunicando algo, é preciso entender que quem comunica, comunica algo a alguém, "mesmo que seja apenas "a quem interessar possa", ou "o transeunte", ou "quem quer que possa, no futuro, ler isto". Assim, quando cremos em alguém, acreditamos também que este alguém entende o que está a nos transmitir e realmente deseja transmitir algo a nós. Assim sendo, mesmo que crença em alguém não possa, como vimos anteriormente, ser reduzida à crença de que alguém diz algo, ela envolve esse tipo de crença e podemos dizer, com Wittgenstein, que nossas crenças isoladas se dão sempre a partir de um sistema de crenças e que "Quando começamos a acreditar em qualquer coisa, aquilo em que acreditamos não é uma proposição isolada, é um sistema completo de proposições” (On Certainty, § 141).

Para além dessas diferenciações, um último ponto, a nosso ver, precisa ser levado em conta quando falamos em crença em alguém, a saber o fato de que a crença em alguém é pré-reflexiva e não se pode confundi-la com 'ser convencido por alguém'. A nosso ver a crença que depositamos em alguém não é uma argumentação, no sentido de que alguém é levado a acreditar através de argumentos. Neste último caso, estaríamos falando de evidências e alguém que crê nas evidências parece estar tendo um crença do tipo crer que $p$. Neste sentido, aquele que é convencido por alguém, acredita na verdade daquilo que ele diz. Acredita nos fatos, não porque confia naquele que lhe transmite tal fato, mas porque foi convencido por ele de tais fatos. $\mathrm{O}$ convencimento parece pressupor a dúvida, no sentido de que é porque não tenho certeza de algo que busco no outro argumentos para minha certeza, porém a dúvida, pressupõe a crença (cf. On Certainty, § 354). No convencimento, alguém é levado a acreditar em algo através das evidências ou argumentos de quem está proferindo determinado conhecimento, já a crença é uma atitude diante de um juízo sobre o mundo. 


\section{Considerações finais}

Com o que vimos, podemos dizer que a crença em alguém é de suma importância para o conhecimetno em geral e fazer um breve resumo das características daquilo que chamamos "crer em alguém": Podemos dizer que as características são as seguintes: 1) crer em alguém difere-se de crer em algo, já que este último tipo de crença é do tipo crer que $p$. 2) Crer em alguém é um crença do tipo crer $x$ que $p$, sendo que a crença em $\mathrm{p}$ depende da crença (ou confiança) que depositamos em $\mathrm{x}$; 2) Crer em alguém não é simplesmente crer que alguém disse algo, apesar de que a crença de que alguém quer nos trasmitir algo está envolvida na crença em alguém; 4) Não se pode confundir crer em alguém com ser convencido por alguém, já que este último pressupõe argumentação e, às vezes, prova.

Assim sendo, parece muito claro que a crença em alguém possui características que a diferenciam da crença direta em um fato. $\mathrm{Na}$ crença em alguém está envolvida questão da confiança naquele que transmite um determinado testemunho. Como boa parte de nossos conhecimento está envolto de crenças que depositamos em fatos decorrentes de testemunho, um estudo aprofundado da epistemologia do testemunho pode nos ajudar e muito a compreender nosso conhecimento em geral. Além disso, um estudo a respeito do tópico crer em alguém é imprescindível, a nosso ver, para a compreensão do discurso religioso, já que este é permeado, em sua totalidade, pelo testemunho vindo de outros crentes e de livros sagrados. Não temos tempo de tratar disso neste trabalho, mas o faremos em outros. Aqui, buscamos, apenas, descrever rapidamente algumas características da crença em alguém. Esperamos ter, ao menos, introduzido tal tópico de forma satisfatória, reconhecendo que para dar conta da totalidade precisaríamos de um texto muito mais extenso. 


\section{Referências}

ANSCOMBE, E. What Is It To Believe Someone? In.: GEACH, M.; GORMALLY, L. (eds.) Faith in a hard ground: essays on religion, philosophy and ethics by G. E. M. Anscombe (Digital Edition). Imprint Academic, 2008. p. 24-33.

COADY, C. A.J. Testimony: A Philosophical Study. Oxford: Oxford University Press, 1995.

LIPTON, P. The Epistemology of Testemony. In.: Studies in History and Philosophy of Science, V 29, n 1, pp. 1-31.

FAULKNER, P. Knowledge on Trust. Oxford: Oxford University Press, 2011.

PRITCHARD, D. The Epistemology of Testimony. In.: Philosophical Issues, 14, 2004. p. 326-348.

RUSSELL, B. Knowledge by Acquaintance and Knowledge by Description. In.: RUSSELL, B. The Basic Writings of Bertrand Russell. London/New York: Routledge, 2010. p. 191-198.

SPICA, M. A. Weltbild, Bezugssystem e crença religiosa. In: João Carlos Salles. (Org.). Certeza. Salvador: Quarteto, 2012. p. 155-172.

WITTGENSTEIN, L. On Certainty (German/English Edition). Trad. G. E. M. Anscombe and Denis Paul. New York: Harper \& Row Publisher, 1972. 